\title{
Synthesis, characterization, and photophysical properties of a thiophene-functionalized bis(pyrazolyl) pyridine (BPP) tricarbonyl rhenium(I) complex $\dagger$
}

\author{
Lauren A. Lytwak, Julie M. Stanley, Michelle L. Mejía and Bradley J. Holliday*
}

Received 21st April 2010, Accepted 7th June 2010

First published as an Advance Article on the web 23rd July 2010

DOI: $10.1039 / \mathrm{codt00357c}$

\begin{abstract}
A bromo tricarbonyl rhenium(I) complex with a thiophene-functionalized bis(pyrazolyl) pyridine ligand $(\mathbf{L}), \operatorname{ReBr}(\mathbf{L})(\mathbf{C O})_{3}(\mathbf{1})$, has been synthesized and characterized by variable temperature and COSY 2-D ${ }^{1} \mathrm{H}$ NMR spectroscopy, single-crystal X-ray diffraction, and photophysical methods. Complex 1 is highly luminescent in both solution and solid-state, consistent with phosphorescence from an emissive ${ }^{3}$ MLCT excited state with an additional contribution from a $\mathrm{LC}^{3}\left(\pi \rightarrow \pi^{*}\right)$ transition. The single-crystal X-ray diffraction structure of the title ligand is also reported.
\end{abstract}

\section{Introduction}

Rhenium diimine complexes are well known for their distinct photophysical properties. In particular, $f a c-(\mathrm{L}) \operatorname{Re}(\mathrm{CO})_{3} \mathrm{X}$, where $\mathrm{L}$ is a bidentate diimine ligand and $\mathrm{X}$ is a halogen, are good phosphorescent materials due to emission from the triplet metal-to-ligand charge transfer $\left({ }^{3} \mathrm{MLCT}\right)$ excited state. ${ }^{1}$ In general, rhenium, like other $\mathrm{d}^{6}$ metals, experience intense phosphorescent emission because of the heavy atom effect. The heavy atom effect allows sufficient mixing of excited singlet and triplet states, giving rise to relatively long-lived microsecond excited state lifetimes and large quantum yields of emission. ${ }^{2}$ Tricarbonyl diimine rhenium complexes are advantageous not only due to efficient phosphorescent emission and microsecond excited state lifetimes, but also because of chemical inertness and ability to undergo redox chemistry. ${ }^{3}$

Because of intense visible region emission, (L) $\operatorname{Re}(\mathrm{CO})_{3} \mathrm{X}$-type complexes have various applications. For example, rhenium(I) diimine complexes show promise in organic light-emitting diodes (OLEDs). OLED devices of other metal complexes, such as iridium, platinum, and osmium, have been reported. ${ }^{4}$ Phosphorescent rhenium complexes have also found uses as biological probes because of their chemical inertness. ${ }^{5}$ Additionally, these complexes are used as photocatalysts and moieties for luminescent and redoxactive supramolecular systems. ${ }^{6}$

Herein, we report the synthesis and photophysical properties of a new thiophene-functionalized bis(pyrazolyl) pyridine (BPP) ligand, L, and corresponding tricarbonyl rhenium(I) complex, $\mathbf{1}$. Incorporation of the thiophene into the BPP ligand is beneficial because extended conjugation lowers the triplet excited state energy level of the ligand and spin-orbit coupling from the heavy sulfur atoms increases the population of the triplet excited state, thereby enhancing phosphorescent quantum yield. In fact, work by de Bettencourt-Dias et al. demonstrated that functionalization

Department of Chemistry \& Biochemistry and Center for Electrochemistry, The University of Texas at Austin, 1 University Station, A5300, Austin, TX 78712-0165.E-mail: bholliday@cm.utexas.edu

$\dagger$ Electronic supplementary information (ESI) available: Variable temperature NMR data and calculated ${ }^{1} \mathrm{H}$ NMR chemical shift $v$ s. dihedral angle plot. CCDC reference numbers 772116 (L) and 764347 (1). For ESI and crystallographic data in CIF or other electronic format see DOI: $10.1039 / \mathrm{c} 0 \mathrm{dt} 00357 \mathrm{c}$ of isophthalic acid with thiophene lowered the triplet state energy by $5000 \mathrm{~cm}^{-1}$, on average. ${ }^{7}$

\section{Results and discussion}

\section{Synthesis of}

2,6-bis[1-methyl-5-(thiophen-2-yl)-pyrazol-3-yl)pyridine (L)

The synthesis of the thiophene-functionalized bis(pyrazolyl) pyridine ligand is outlined in Scheme 1. The title ligand, $\mathbf{L}$, was synthesized by modification of literature procedures. ${ }^{8}$ In summary, the trans-esterification of acetylthiophene and dimethyl pyridine2,6-dicarboxylate formed a tetraketone synthetic intermediate in $77 \%$ yield (Scheme 1, top right). Treatment of the tetraketone with hydrazine hydrate in a condensation reaction produced the protonated pyrazolyl pyridine species $\left(\mathbf{H}_{2} \mathbf{L}\right)$. The desired ligand was then formed by alkylation of the pyrazoles with sodium hydride and methyl iodide.

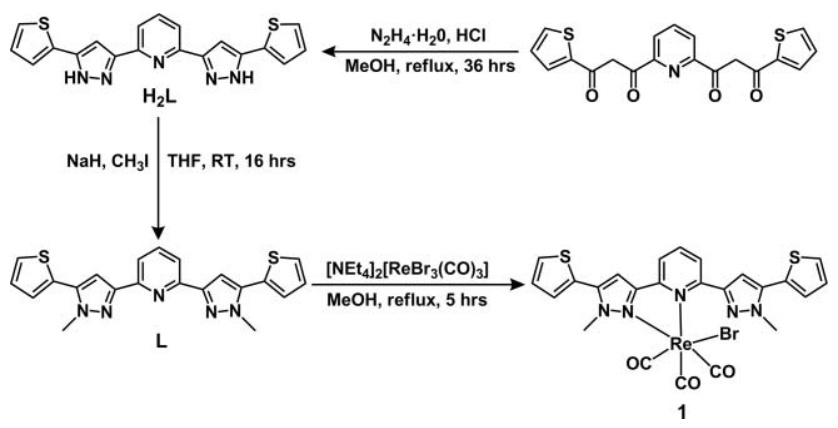

Scheme 1 Synthesis of complex 1.

\section{X-Ray crystallography of $L$}

X-Ray quality crystals of $\mathbf{L}$ were obtained by slow diffusion of hexanes into a saturated dichloromethane solution. Fig. 1A shows the asymmetric unit containing one molecule of $\mathbf{L}$ while Fig. 1B shows the close packing of two molecules in the unit cell. Selected bond lengths and angles for $\mathbf{L}$ are shown in Table 3 . The pyrazole rings are in a nearly coplanar arrangement with the 
central pyridine ring with the nitrogens of the pyrazoles (N7/N13, Fig. 1A) in a s-trans configuration. As shown in the single molecule crystal structure in Fig. 1A, the thiophene rings (containing S1aa and S1ae) are twisted slightly from the plane of the pyrazole rings, as indicated by dihedral angles of $0.63^{\circ}$ and $6.29^{\circ}$, respectively. However, in the close packing unit cell (Fig. 1B), the thiophene rings of the second ligand molecule are twisted $13.39^{\circ}$ and $7.19^{\circ}$ with respect to the pyrazole rings. This is consistent with the work of You et al. wherein they report dihedral angles of $5.3^{\circ}$ and $3.5^{\circ}$ for a phenyl subsituted BPP ligand. ${ }^{9 b}$ Interestingly, Thiel and coworkers report a much more twisted solid state geometry when electron deficient aromatic rings are appended. This group observes dihedral angles of $66.2^{\circ}$ and $61.3^{\circ}$ for nitroarylated BPP derivatives. ${ }^{9 \mathrm{c}}$ The angle between the two ligand molecules in the close packing unit cell is $87.43^{\circ}$. The remaining structural features (e.g., bond lengths and angles) closely agree with that of analogous BPP structures. ${ }^{9}$
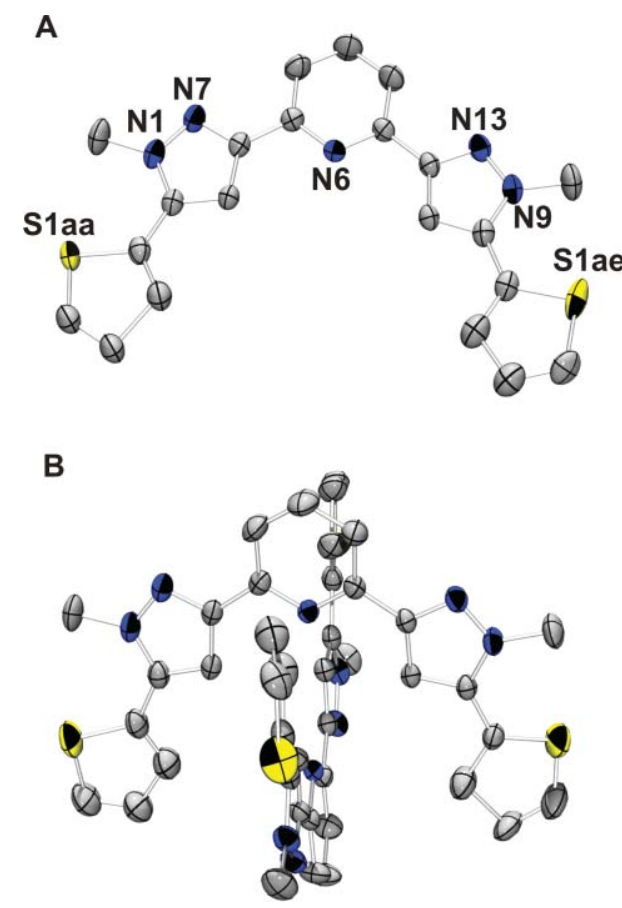

Fig. 1 (A) ORTEP diagram of a single molecule of $\mathbf{L}$, showing the labeling scheme of selected atoms. Thermal ellipsoids are shown at the $50 \%$ probability level. Hydrogen atoms have been omitted for clarity. (B) Close packing of two molecules in the unit cell.

\section{Synthesis of $f a c-\operatorname{ReBrL}(\mathrm{CO})_{3}(1)$}

Complex 1 was prepared by refluxing $\mathbf{L}$ with $\left[\mathrm{NEt}_{4}\right]_{2}\left[\operatorname{ReBr}_{3}(\mathrm{CO})_{3}\right]$ for $5 \mathrm{~h}$ in methanol, as shown in Scheme 1. The desired product, $\operatorname{ReBrL}(\mathrm{CO})_{3}$, was obtained in $50 \%$ yield, without further purification. Complex 1 has three bound carbonyls, as indicated by the three IR peaks in the carbonyl stretching region: $2014 \mathrm{~cm}^{-1}$, $1907 \mathrm{~cm}^{-1}$, and $1867 \mathrm{~cm}^{-1}$. This agrees with the IR spectrum predicted by group theory analysis. ${ }^{10}$ All other spectroscopic, highresolution mass spectrometry, and combustion analysis data for $\mathbf{1}$, and the corresponding precursors are consistent with the proposed structures.

\section{NMR studies of 1}

To further elucidate the solution structure of complex $\mathbf{1}$, detailed ${ }^{1} \mathrm{H}$ NMR experiments were performed. The COSY 2-D NMR of complex 1, shown in Fig. 2, confirms a break in symmetry of the ligand upon complexation with rhenium that results from coordination to only two of the three nitrogens of the ligand. The ability to record a spectrum with sharp resonances present for each proton in the molecule indicates that the movement of the rhenium metal center within the binding pocket of the ligand (i.e., exchange of the free and bound pyrazolyl ligands, or tick-tock exchange ${ }^{11}$ ) is absent or slow on the NMR timescale. The COSY ${ }^{1} \mathrm{H}$ NMR data shown in Fig. 2 also confirms that the solution structure of $\mathbf{1}$ is the same as the solid-state structure, determined by X-ray crystallography, shown in Fig. 4 (vide infra). Peak density off the diagonal of the 2-D NMR spectrum show protons that are strongly coupled. For example, a correlation is observed between the central proton of the pyridine $(\mathrm{G})$ and the $\mathrm{F}$ and $\mathrm{F}^{\prime}$ protons on either side of it. Observed chemical shifts unperturbed relative to that of the free ligand are assigned as signals from protons of the unbound side of the ligand (Fig. 2).

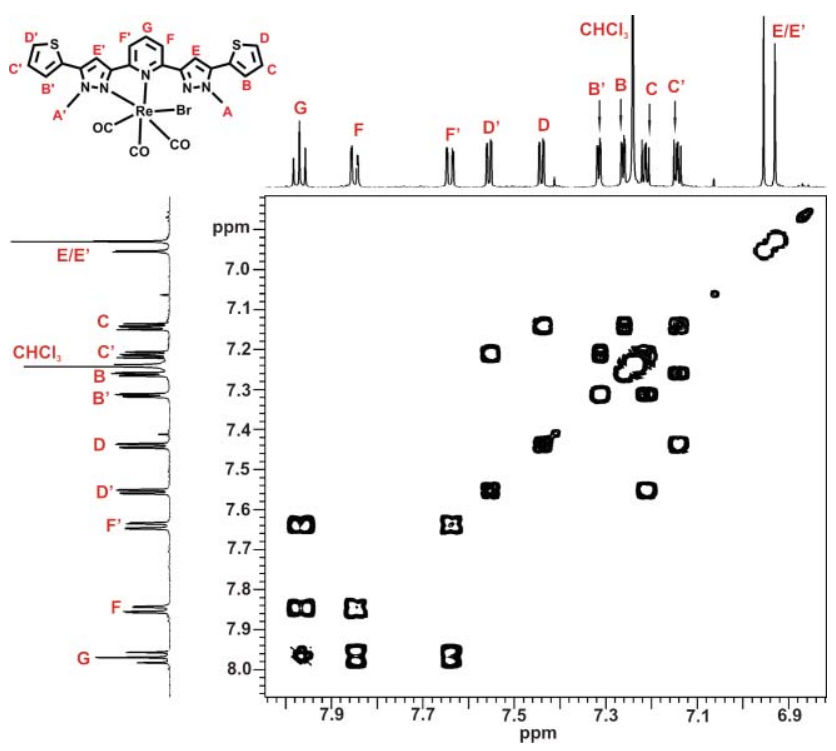

Fig. 2 Aromatic expansions of the COSY 2-D ${ }^{1} \mathrm{H}$ NMR of 1 in $\mathrm{CDCl}_{3}$ at room temperature.

Variable temperature NMR experiments of 1 were performed in 1,1,2,2-tetrachloroethane- $\mathrm{d}_{2},\left(\mathrm{CDCl}_{2}\right)_{2}$, from 300 to $400 \mathrm{~K}$. At high temperatures, no coalescence of equivalent protons on the bound and unbound sides of the ligand was observed (e.g., $\mathrm{F} / \mathrm{F}^{\prime}$ or $\left.\mathrm{E} / \mathrm{E}^{\prime}\right)$, indicating that no tick-tock movement of the ligand about the rhenium metal center is present within this temperature range (see ESI for spectra). The one notable change in the ${ }^{1} \mathrm{H}$ NMR spectrum with temperature is the E proton on the unbound side of the ligand shifts to lower field with increasing temperature while the $\mathrm{E}^{\prime}$ proton on the bound side of the ligand experiences no change in chemical shift (Fig. 3A). The observed change in chemical shift of the $\mathrm{E}$ proton is attributed to a change in the dihedral angle between the central pyridine ring and pyrazole ring of the unbound side of the ligand at elevated temperatures. Fig. 3B depicts the chemical shift of the $\mathrm{E}$ and $\mathrm{E}^{\prime}$ protons as a function of the dihedral angle between the pyridine and unbound pyrazole, 


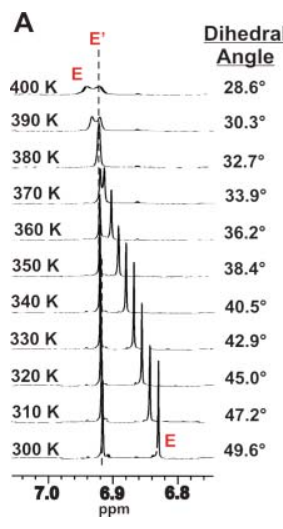

B

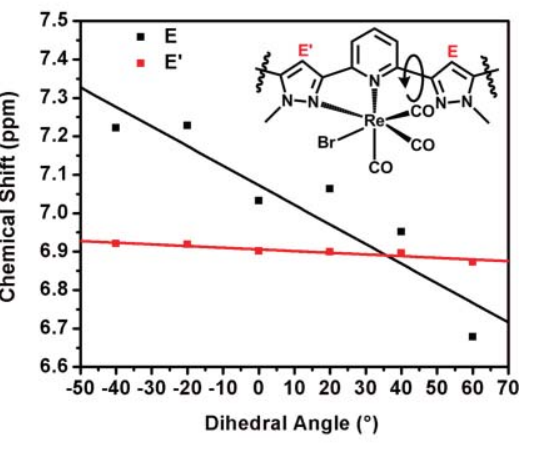

Fig. 3 (A) Variable temperature ${ }^{1} \mathrm{H}$ NMR of 1 showing the $\mathrm{E}$ and $\mathrm{E}^{\prime}$ protons in $\left(\mathrm{CDCl}_{2}\right)_{2}$, with corresponding dihedral angle. (B) Chemical shift versus dihedral angle plot of $\mathbf{1}$, as determined by Gaussian calculations.

as determined by Gaussian nuclear magnetic resonance shielding tensor calculations. Dihedral angles similar to that displayed in the X-ray crystal structure $\left(\sim 47^{\circ}\right)$ were of particular interest. As shown in Fig. 3B, the chemical shift of $\mathrm{E}^{\prime}$ remains fairly constant as the dihedral angle is varied. However, the chemical shift of E changes as this proton is initially deshielded by through-space interactions with the proton on the adjacent pyridine ring $(\mathrm{F}$, Fig. 2) as the dihedral angle approaches $0^{\circ}$. Proton $E$ is then further deshielded by through-space interactions with the ancillary ligands on the metal center, particularly the nearest carbonyl group, as the dihedral angle becomes increasingly negative. This incremental deshielding of $\mathrm{E}$ is a function of the dihedral angle as the $\mathrm{E}$ proton rotates towards the neighboring carbonyl (Fig. 3). The relative difference between chemical shifts $\mathrm{E}$ and $\mathrm{E}^{\prime}$, as determined by Fig. 3B, were compared to the difference in chemical shifts of $E$ and $\mathrm{E}^{\prime}$ in the experimental spectra (Fig. 3A) to assign a dihedral angle present in the equilibrium geometry of the time-averaged signal at each particular temperature. For example, this correlation between the theoretical and experimental data indicates that the dihedral angle of $\mathbf{1}$ is $49.6^{\circ}$ at room temperature which is in agreement with the solid-state geometry determined by X-ray diffraction. As the temperature is increased, the unbound side of the ligand is given enough energy to twist, as exemplified by a dihedral angle of $28.6^{\circ}$ at $400 \mathrm{~K}$. The decrease in dihedral angle, and corresponding approach towards planarity of the three nitrogen atoms in the ligand, observed in $\mathbf{1}$ with increasing temperature, is consistent with the lack of tick-tock movement in $\mathbf{1}$ which is observed for similar complexes..$^{11}$ Moreover, it is this molecular twisting motion which precludes the exchange of the metal center between the two equivalent positions by introducing an additional activation energy to the exchange which is associated with planarizing the ligand.

\section{X-Ray crystallography of 1}

Crystals suitable for single-crystal X-ray diffraction analysis were grown by slow diffusion of hexanes into a saturated solution of 1 in dichloromethane. As shown in Fig. 4, the three carbonyl ligands are arranged in a facial fashion about the rhenium metal center, thus causing the nearly planar $\mathbf{L}$ to bind in a bidentate mode with one pyrazolyl ring twisted $\left(47^{\circ}\right)$ out of plane. Similar dihedral angles have been reported for rhenium complexes in which terdentate ligands behave as bidentate chelates. Hor et al. report a dihedral angle of $42.3^{\circ}$ for the unbound pyridine of a $\operatorname{Re}($ terpy $) \operatorname{Br}(\mathrm{CO})_{3}$ complex. ${ }^{12 b}$ In contrast, Jones and Heard report a chloro tricarbonyl rhenium complex containing a bis(oxazole)pyridine ligand in which the unbound oxazole ring is twisted $76.2^{\circ}$ out of planarity. ${ }^{11 \mathrm{c}}$ The rhenium is in a distorted octahedral environment, as made evident by $\mathrm{C}(3)-\mathrm{Re}-\mathrm{N}(4)$ and $\mathrm{Br}-\mathrm{Re}-\mathrm{N}(3)$ bond angles of $101.7^{\circ}$ and $82.6^{\circ}$, respectively. The average $\mathrm{Re}-\mathrm{C}$ and $\mathrm{Re}-\mathrm{N}$ bond distances, $1.912 \AA$ and $2.199 \AA$ respectively, agree closely to those bond distances found in similar structures. ${ }^{2 a, 6 h, 12}$ Additonal bond lengths and angles of 1 are shown in Table 4.

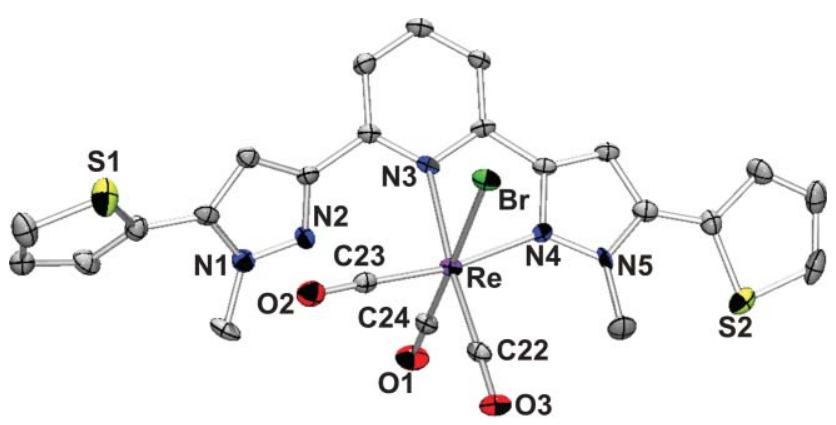

Fig. 4 ORTEP diagram of $\mathbf{1}$, thermal ellipsoids drawn at 30\% probability level, showing the labeling scheme of selected atoms. Hydrogen atoms have been omitted for clarity.

\section{Photophysical studies of $\mathbf{L}$}

The photophysical properties of $\mathbf{L}$ are summarized in Table 1 . In solution, the absorption spectrum (Fig. 5A) shows an intense absorption band at $251 \mathrm{~nm}\left(\varepsilon=5.63 \times 10^{4} \mathrm{M}^{-1} \mathrm{~cm}^{-1}\right)$ with lowerenergy shoulders at 270 and $305 \mathrm{~nm}$. The room temperature emission spectrum, when excited at $250 \mathrm{~nm}$, displays a maximum at $341 \mathrm{~nm}$. This emission peak can be attributed to ligand

Table 1 Photophysical properties of $\mathbf{L}$ and $\mathbf{1}$

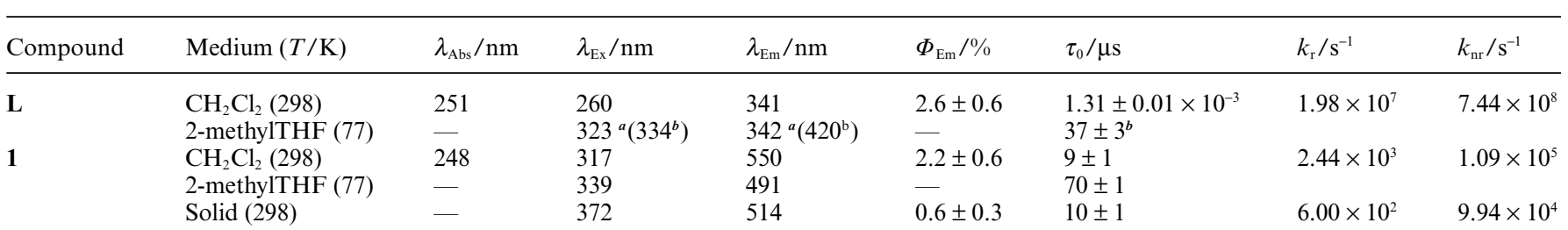

${ }^{a}$ Ligand fluorescence data. ${ }^{b}$ Ligand phosphorescence data. 

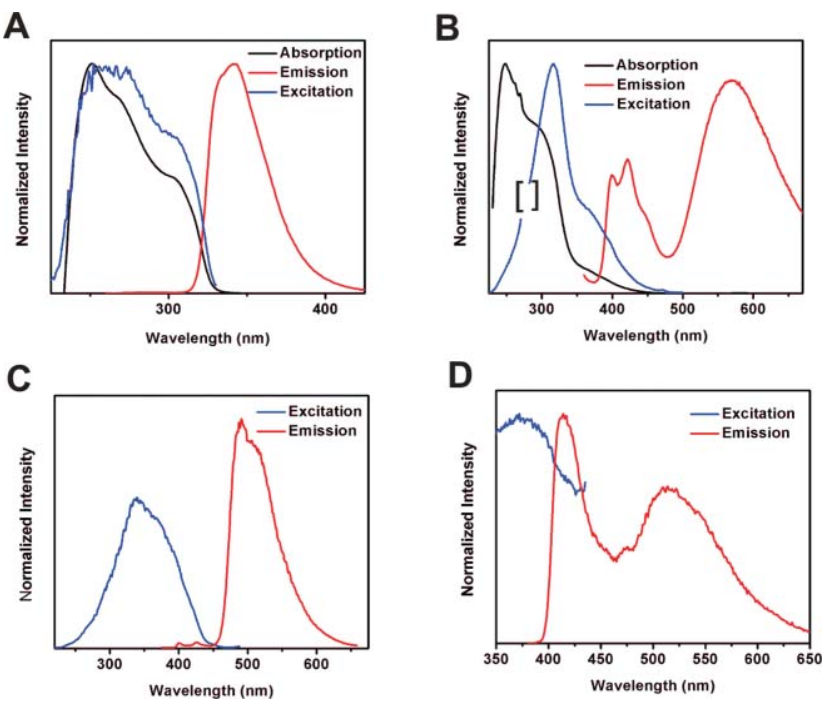

Fig. 5 (A) Absorption, emission, and excitation spectra of $\mathbf{L}$ at room temperature in $\mathrm{CH}_{2} \mathrm{Cl}_{2}$. (B) Absorption, emission, and excitation spectra of $\mathbf{1}$ at room temperature in $\mathrm{CH}_{2} \mathrm{Cl}_{2}$. Brackets in excitation profile indicate an omitted peak due to half of the monitored emission wavelength. (C) Emission and excitation of $\mathbf{1}$ at $77 \mathrm{~K}$ in 2-methyltetrahydrofuran. (D) Emission and excitation of $\mathbf{1}$ at room temperature in the solid state.

fluorescence $\left(\Phi_{\mathrm{fl}}=2.6 \%\right)$ due to determination of a relatively short excited state lifetime ( $\tau=1.31 \pm 0.01 \mathrm{~ns})$. Upon cooling to $77 \mathrm{~K}$, ligand phosphorescence is observed, centered at $420 \mathrm{~nm}$ (Table 1). A large Stokes shift from ligand absorption and longlived excited-state lifetime ( $\tau=37 \pm 3 \mu$ s) confirm the emission is phosphorescence.

\section{Photophysical studies of 1}

The solution and solid-state photophysical properties of $\mathbf{1}$ were studied and are summarized in Table 1. As shown in Fig. 5B, 1 displays a similar absorption profile to that of $\mathbf{L}$ with the notable differences being a red shift of the ligand peak at $305 \mathrm{~nm}$ to $317 \mathrm{~nm}$ and a broad low energy band from $\sim 350-425 \mathrm{~nm}$. The later is indicative of a metal-to-ligand charge transfer (MLCT) $d$ $\rightarrow \pi^{*}$ transition. ${ }^{2,13,14}$ The room temperature emission spectrum (Fig. 5B) shows a set of peaks from $380-470 \mathrm{~nm}$ and an intense broad peak at $550 \mathrm{~nm}$. The peaks from $380-470 \mathrm{~nm}\left(\lambda_{\max }=420\right.$ $\mathrm{nm})$ correspond to ligand phosphorescence emission $(\tau=10 \pm 1$ $\mu \mathrm{s})$. The ligand's triplet excited state energy level, when bound to rhenium, is measured as $25,000 \mathrm{~cm}^{-1}$, which is unchanged relative to that of free ligand. Based on previous luminescence studies of rhenium(I) diimine tricarbonyl complexes, the intense emission band at $550 \mathrm{~nm}$ is assigned as ${ }^{3}$ MLCT phosphorescence emission $\left(\Phi_{\mathrm{ph}}=2.2 \%\right)^{1,2 a, 5 \mathrm{a}, 10 \mathrm{c}, 13,14}$ Monitoring changes in emission intensity of 1 at $550 \mathrm{~nm}$ while varying excitation wavelength produces an excitation profile that displays two overlapping components (Fig. 5B). A matching excitation profile is also obtained when monitoring the emission peaks at $420 \mathrm{~nm}$, corresponding to ligand phosphorescence. This suggests a mixed excited state for $\mathbf{1}$ with both ${ }^{3} \mathrm{LC}$ (ligand centered) and ${ }^{3} \mathrm{MLCT}$ character. ${ }^{15}$ The two components observed in the excitation profile of $\mathbf{1}$ are assigned to $\pi \rightarrow \pi^{*}$ absorption by the bound ligand centered at $310 \mathrm{~nm}$ and ${ }^{1}$ MLCT absorption centered at $375 \mathrm{~nm}$. This interpretation is strongly supported by considering the phosphorescence excitation spectrum of the free ligand at $77 \mathrm{~K}$ which is similar in position and profile to the higher energy component observed in the excitation profile of 1 . Schanze and coworkers report similar findings in which excitation of a tricarbonyl rhenium diimine analogue populates both MLCT and IL excited states. ${ }^{16}$

Upon cooling to $77 \mathrm{~K}$, the major emission band remains broad and structureless but experiences a significant blue shift. This blue shift upon cooling further confirms that the emissive state is ${ }^{3} \mathrm{MLCT}$ in nature. The ligand phosphorescent peaks at 380 $470 \mathrm{~nm}$ are still present at $77 \mathrm{~K}(\tau=9.7 \pm 0.6 \mu \mathrm{s})$ but are much less intense than at room temperature indicating that upon cooling, the emission is dominated by the ${ }^{3}$ MLCT character of the mixed excited state. Additionally, the lack of any observed shift in the position of the peaks at $380-470 \mathrm{~nm}$ with cooling further supports the assignment of these peaks as a $\operatorname{LC}^{3}\left(\pi \rightarrow \pi^{*}\right)$ transition. Solidstate luminescence experiments were conducted on drop cast films of 1 . The ${ }^{3}$ MLCT band is blue shifted in the solid-state emission spectrum and there is a decrease in the absolute quantum yield from $2.2 \%$ to $0.6 \%$ (Fig. 5D). The ${ }^{3} \mathrm{LC}$ peak ( $\tau=8.5 \pm 0.9 \mu \mathrm{s}$ ) loses its structure in the solid-state but does not exhibit a shift in position.

\section{Experimental}

\section{General}

All chemicals were purchased from commercial sources and used as received. All of the solvents used, with the exception of methanol, were dried using an Innovative Technology, Pure Solv solvent purifier with a double purifying column. $\left[\mathrm{NEt}_{4}\right]_{2}\left[\operatorname{ReBr}_{3}(\mathrm{CO})_{3}\right]$ was prepared according to the reported procedure. ${ }^{17} \mathrm{H}$ NMR (300 MHz) and ${ }^{13} \mathrm{C}\left\{{ }^{1} \mathrm{H}\right\}$ NMR $(75 \mathrm{MHz})$ spectra were obtained on a Varian $(300 \mathrm{MHz})$ spectrometer and were referenced to residual solvent peaks. All peak positions are given in ppm and coupling constants are reported in Hz. Lowresolution and high-resolution mass spectrometry was carried out by a Thermo Finngan TSQ 700 and Waters Autospec Ultima, respectively. Elemental analysis was performed by QTI, Whitehouse, $\mathrm{NJ}$ (www.qtionline.com). Infrared spectra were recorded using a Nicolet IR 200 FTIR spectrophotometer. All spectroscopic data were obtained in methylene chloride solutions unless otherwise noted. Absorption spectra were recorded on a Varian Cary 6000i UV-VIS-NIR spectrophotometer with Starna Quartz fluorometer cells with a pathlength of $10 \mathrm{~mm}$. Luminescent measurements were recorded on a Photon Technology International QM 4 spectrophotometer equipped with a 6-inch diameter K Sphere$\mathrm{B}$ integrating sphere. Measurements at $77 \mathrm{~K}$ were recorded using an optical liquid nitrogen Dewar sample holder. Lowtemperature samples were made in 2-methyltetrahydrofuran in quartz $4 \mathrm{~mm}$ outer diameter EPR tubes. Ligand triplet state energies were calculated by using the wavelength corresponding to the onset of ligand phosphorescence and converting to $\mathrm{cm}^{-1}$. Ligand phosphorescent data and lifetimes were acquired from airfree samples made in deoxygenated freeze-pump-thawed (four cycles) 2-methyltetrahydrofuran in quartz $4 \mathrm{~mm}$ outer diameter EPR tubes. For quantum yield measurements, the integrating sphere was used. Quantum yield was calculated by dividing the area under the emission peak of the sample by the difference between the area under the excitation peak of the sample from 
that of a blank solution ( $A_{\text {em sample }} /\left(A_{\text {ex blank }}-A_{\text {ex sample })}\right.$, where $A=$ area under peak $){ }^{18}$ Radiative and non-radiative rate constants $\left(k_{\mathrm{r}}\right.$ and $k_{\mathrm{nr}}$ ) were calculated using eqn (1) and (2), respectively. ${ }^{2 \mathrm{~d}}$

$$
\begin{gathered}
k_{\mathrm{r}}=\Phi_{\mathrm{em}} / \tau \\
k_{\mathrm{nr}}=\left(1-\Phi_{\mathrm{em}}\right) / \tau
\end{gathered}
$$

\section{Synthesis of 2,6-Bis(1'(thiophen-2-yl)-1',3'dioxopropyl)pyridine}

Prepared with slight modification to a literature procedure described by Fenton et al. ${ }^{8}$ Under an inert atmosphere of argon, sodium ethoxide was prepared in situ upon addition of ethanol $(15 \mathrm{~mL})$ to $\mathrm{NaH}(0.6717 \mathrm{~g}, 26.6 \mathrm{mmol})$. To the freshly prepared sodium ethoxide, 2-acetylthiophene $(3.31 \mathrm{~mL}, 30.7 \mathrm{mmol})$ in dry toluene was added, followed quickly by dimethyl pyridine-2,6dicarboxylate $(2.00 \mathrm{~g}, 10.2 \mathrm{mmol})$. The solution was stirred for $16 \mathrm{~h}$ at room temperature. After stirring at $60{ }^{\circ} \mathrm{C}$ for $4 \mathrm{~h}$, the solution was filtered and washed with diethyl ether. The yellow solid was then added to a vigorously stirred solution of acetic acid and water. Product was recovered from the aqueous solution by addition of methylene chloride. The resulting solution was then washed with three $75 \mathrm{~mL}$ portions of a $6 \%$ sodium bicarbonate solution and deionized water and dried over anhydrous magnesium sulfate. Upon recrystallization in methylene chloride and hexanes, a yellow feathery solid was recovered (1.58 g, 40\%). The purity and composition of the target compound was confirmed by comparison of the ${ }^{1} \mathrm{H}$ and ${ }^{13} \mathrm{C}\left\{{ }^{1} \mathrm{H}\right\}$ NMR spectroscopy data to literature values. ${ }^{8}$

\section{Synthesis of 2,6-Bis[1 H-5-(thiophen-2-yl)-pyrazol-3-yl]pyridine $\left(\mathbf{H}_{2} \mathbf{L}\right)$}

A mixture of 2,6-Bis(1'(thiophen-2-yl)-1',3'dioxopropyl)pyridine $(0.4 \mathrm{~g}, 1.0 \mathrm{mmol})$, hydrazine monohydrate $(80 \%, 1.10 \mathrm{~mL}, 17.7$ mmol) and a few drops of concentrated $\mathrm{HCl}$ in methanol were refluxed for $36 \mathrm{~h}$. After reducing the solution to approximately $5 \mathrm{~mL}$, water was added to precipitate a tan solid. The product was isolated from the solution by filtration and dried in vacuo to yield a tan powder $(0.31 \mathrm{~g}, 80 \%)$ : mp: decomp. at $285{ }^{\circ} \mathrm{C}$; ${ }^{1} \mathrm{H} \mathrm{NMR}$ (DMSO-d D $_{6}: 13.54$ (s, 2H), $8.00(\mathrm{~s}, 1 \mathrm{H}), 7.83(\mathrm{~s}, 2 \mathrm{H}), 7.47(\mathrm{~s}, 4 \mathrm{H})$, 7.39 (s, 2H), 7.14 (s, 2H); The compound was not soluble enough in any common organic solvent for ${ }^{13} \mathrm{C}\left\{{ }^{1} \mathrm{H}\right\}$ NMR analysis; UVVis $\left(\mathrm{CH}_{3} \mathrm{OH}, \mathrm{nm}\right): \lambda_{\max } 274\left(\varepsilon, 3.75 \times 10^{4} \mathrm{M}^{-1} \mathrm{~cm}^{-1}\right)$; HRMS (CI+) calcd. for $\mathrm{C}_{19} \mathrm{H}_{13} \mathrm{~N}_{5} \mathrm{~S}_{2}$ : 375.0612. Found 375.0612.

\section{Synthesis of 2,6-Bis[1-methyl-5-(thiophen-2-yl)-pyrazol-3- yllpyridine (L)}

Under an inert atmosphere of argon, $\mathrm{NaH}$ (0.02 g, $0.97 \mathrm{mmol})$ and dry THF $(20 \mathrm{~mL})$ were combined to create a suspension. Upon addition of $\mathbf{H}_{2} \mathbf{L}(0.15 \mathrm{~g}, 0.40 \mathrm{mmol})$, a white precipitate formed. The resulting solution was stirred under argon at room temperature for $2 \mathrm{~h}$ and treated with methyl iodide $(0.06 \mathrm{~mL}$, $0.90 \mathrm{mmol}$ ). After stirring overnight, $\mathrm{H}_{2} \mathrm{O}$ was added to produce a cloudy white solution. The product was extracted with chloroform and solvent was removed to yield a pale yellow solid $(0.13 \mathrm{~g}, 81 \%)$ : mp: $236-240{ }^{\circ} \mathrm{C} ;{ }^{1} \mathrm{H}$ NMR $\left(\mathrm{CDCl}_{3}\right): 7.88(\mathrm{~m}, 2 \mathrm{H}), 7.75(\mathrm{dd}, J=$ $6.9,8.5,1 \mathrm{H}), 7.41(\mathrm{dd}, J=0.9,4.9,2 \mathrm{H}), 7.23(\mathrm{dd}, J=1.2,3.6$, $2 \mathrm{H}), 7.15(\mathrm{~s}, 2 \mathrm{H}), 7.13(\mathrm{dd}, J=3.6,5.1,2 \mathrm{H}), 4.05(\mathrm{~s}, 6 \mathrm{H}) ;{ }^{13} \mathrm{C}\left\{{ }^{1} \mathrm{H}\right\}$
NMR: 151.6, 150.9, 138.0, 137.1, 131.3, 127.6, 127.0, 126.6, 118.5, 105.8, 38.2; UV-Vis $\left(\mathrm{CH}_{2} \mathrm{Cl}_{2}, \mathrm{~nm}\right): \lambda_{\max } 249\left(\varepsilon, 5.56 \times 10^{4} \mathrm{M}^{-1} \mathrm{~cm}^{-1}\right)$; HRMS (CI+) calcd. for $\mathrm{C}_{21} \mathrm{H}_{17} \mathrm{~N}_{5} \mathrm{~S}_{2}$ : 403.0925. Found 403.0932; Anal. calcd. for $\mathrm{C}_{21} \mathrm{H}_{17} \mathrm{~N}_{5} \mathrm{~S}_{2}$ : C, 62.51; H, 4.25; N, 17.36. Found: C, 62.17; H, 4.16; N, 17.17.

\section{Synthesis of $f a c-\operatorname{ReLBr}(\mathrm{CO})_{3}(1)$}

Ligand, L, (0.055 g, $0.14 \mathrm{mmol})$ in methanol $(25 \mathrm{~mL})$ was added to a stirred solution of $\left[\mathrm{NEt}_{4}\right]_{2}\left[\operatorname{ReBr}_{3}(\mathrm{CO})_{3}\right]^{17}(0.10 \mathrm{~g}, 0.14 \mathrm{mmol})$ in methanol $(20 \mathrm{~mL})$. The solution was refluxed for $5 \mathrm{~h}$ to yield a cloudy yellow-green solution. Solvent was removed to yield a green solid. (0.052 g, 50\%): mp: decomp. at $267{ }^{\circ} \mathrm{C} ;{ }^{1} \mathrm{H} \mathrm{NMR}$ $\left(\mathrm{CDCl}_{3}\right): 7.97(\mathrm{t}, J=7.8,1 \mathrm{H}), 7.85(\mathrm{dd}, J=1.8,7.8,1 \mathrm{H}), 7.64$ $(\mathrm{dd}, J=1.2,7.8,1 \mathrm{H}), 7.56(\mathrm{dd}, J=1.2,4.8,1 \mathrm{H}), 7.44(\mathrm{dd}, J=$ $1.2,4.8,1 \mathrm{H}), 7.31(\mathrm{dd}, J=1.2,3.3,1 \mathrm{H}), 7.26(\mathrm{dd}, J=1.2,3.0$, $1 \mathrm{H}), 7.21(\mathrm{dd}, J=3.6,5.4,1 \mathrm{H}), 7.14(\mathrm{dd}, J=3.6,5.4,1 \mathrm{H}), 6.95$ $(\mathrm{s}, 1 \mathrm{H}), 6.93(\mathrm{~s}, 1 \mathrm{H}), 4.22(\mathrm{~s}, 3 \mathrm{H}), 4.07(\mathrm{~s}, 3 \mathrm{H})$; The compound was not soluble enough in any common organic solvent for ${ }^{13} \mathrm{C}$ $\left\{{ }^{1} \mathrm{H}\right\}$ NMR analysis; UV-Vis $\left(\mathrm{CH}_{2} \mathrm{Cl}_{2}, \mathrm{~nm}\right): \lambda_{\max } 245(\varepsilon, 2.12 \times$ $10^{4} \mathrm{M}^{-1} \mathrm{~cm}^{-1}$ ); IR ( $\left.\mathrm{cm}^{-1}\right): v_{\mathrm{CO}}, 2014$ (s), 1908 (s), 1867 (s); HRMS (ESI) calcd. for $\mathrm{C}_{24} \mathrm{H}_{17} \mathrm{~N}_{5} \mathrm{O}_{3} \mathrm{~S}_{2} \mathrm{Re}^{+1}$ : 674.0329. Found 674.03248; Anal. calcd. for $\mathrm{C}_{24} \mathrm{H}_{17} \mathrm{BrN}_{5} \mathrm{O}_{3} \mathrm{ReS}_{2}$ : C, 38.25; H, 2.27; N, 9.29. Found: C, 38.02; H, 2.69; N, 8.88.

\section{Structure refinement of $\mathbf{L}$}

The crystallographic data and structure refinement details for $\mathbf{L}$ are listed in Table 2. Selected bond lengths $(\AA)$ and angles $\left(^{\circ}\right)$ for $\mathbf{L}$ are given in Table 3 . The data were collected on a Rigaku SCX-Mini diffractometer with a Mercury CCD using a graphite monochromator with Mo-K $\alpha$ radiation $(\lambda=0.71073 \AA)$. A total of 337 frames of data were collected using $\omega$-scans with a scan range of $1^{\circ}$ and a counting time of $60 \mathrm{~s}$ per frame. The data were collected at $223 \mathrm{~K}$ using a Rigaku Tech50 low temperature device. Data reduction was performed using the Rigaku Americas Corporation's Crystal Clear version 1.40. ${ }^{19}$ The structure was solved by direct methods using SIR $97^{20}$ and refined by full-matrix least-squares on $\mathrm{F}^{2}$ with anisotropic displacement parameters for the non-H atoms using SHELXL-97. ${ }^{21}$ The absolute configuration was assigned by internal comparison to the known absolute configuration of selected portions of the molecule. The hydrogen atoms on carbon were calculated in ideal positions with isotropic displacement parameters set to $1.2 \mathrm{xUeq}$ of the attached atom (1.5xUeq for methyl hydrogen atoms). The function, $\sum w\left(\left|F_{\mathrm{o}}\right|^{2}-\right.$ $\left.\left|F_{\mathrm{c}}\right|^{2}\right)^{2}$, was minimized, where $w=1 /\left[\left(\sigma\left(F_{\mathrm{o}}\right)\right)^{2}+\left(0.0528^{*} P\right)^{2}\right]$ and $P=\left(\left|F_{\mathrm{o}}\right|^{2}+2\left|F_{\mathrm{c}}\right|^{2}\right) / 3 . R_{\mathrm{w}}\left(F^{2}\right)$ refined to 0.107 , with $R(F)$ equal to 0.0459 and a goodness of fit, $S=1.04$. Definitions used for calculating $R(F), R_{\mathrm{w}}\left(F^{2}\right)$ and the goodness of fit, $\mathrm{S}$, are given below. ${ }^{22}$ The data was checked for secondary extinction effects but no correction was necessary. Neutral atom scattering factors and values used to calculate the linear absorption coefficient are from the International Tables for X-ray Crystallography (1992). ${ }^{23}$ All figures were generated using ORTEP.

\section{Structure refinement of 1}

The crystallographic data and structure refinement details for $\mathbf{1}$ are listed in Table 2 and selected bond lengths $(\AA)$ and angles $\left(^{\circ}\right)$ are given in Table 4. Data for 1 was collected on a Nonius Kappa CCD 
Table 2 Crystal data and structure refinement for $\mathbf{L}$ and $\mathbf{1}$

\begin{tabular}{|c|c|c|}
\hline & $\mathbf{L}$ & 1 \\
\hline Formula & $\mathrm{C}_{21} \mathrm{H}_{17} \mathrm{~N}_{5} \mathrm{~S}_{2}$ & $\mathrm{C}_{24} \mathrm{H}_{17} \mathrm{BrN}_{5} \mathrm{O}_{3} \mathrm{ReS}_{2}$ \\
\hline Fw & 403.52 & 753.66 \\
\hline Crystal syst. & Triclinic & Monoclinic \\
\hline Space group & $P \overline{1}$ & $P 21 / n$ \\
\hline$a / \AA ̊$ & $10.045(2)$ & $14.664(2)$ \\
\hline$b / \AA ̊$ & $10.104(2)$ & $9.8970(10)$ \\
\hline$c / \AA ̊$ & $20.422(4)$ & $17.330(2)$ \\
\hline$\alpha\left(^{\circ}\right)$ & $100.221(8)$ & 90 \\
\hline$\beta\left(^{\circ}\right)$ & $101.683(9)$ & $102.493(2)$ \\
\hline$\gamma\left({ }^{\circ}\right)$ & $91.634(8)$ & 90 \\
\hline$V / \AA^{3}$ & 1993.1(7) & $2455.5(5)$ \\
\hline$Z$ & 4 & 4 \\
\hline$D_{\mathrm{c}} / \mathrm{g} \mathrm{cm}^{-3}$ & 1.345 & 2.039 \\
\hline$T / \mathrm{K}$ & $223(2)$ & $100(2)$ \\
\hline$F(000)$ & 840 & 1448 \\
\hline$\mu / \mathrm{mm}^{-1}$ & 0.284 & 6.784 \\
\hline$\Theta$ range $/^{\circ}$ & $2.99-27.50$ & $4.60-27.50$ \\
\hline Index ranges & $\begin{array}{l}-13 \leq h \leq 12 \\
-12 \leq k \leq 13 \\
-26 \leq l \leq 26\end{array}$ & $\begin{array}{l}-19 \leq h \leq 19 \\
-12 \leq k \leq 12 \\
-22 \leq l \leq 22\end{array}$ \\
\hline Absorption correction & Multi-scan & $\begin{array}{l}\text { Semi-empirical } \\
\text { from equivalents }\end{array}$ \\
\hline $\begin{array}{l}\text { Max. and min. } \\
\text { transmission }\end{array}$ & $0.9172,0.8326$ & $1.00,0.385$ \\
\hline Gof on $F^{2}$ & 1.056 & 1.843 \\
\hline $\begin{array}{l}\text { Largest diff. peak and } \\
\text { hole/e } \AA^{-3}\end{array}$ & 0.509 and -0.551 & 3.192 and -2.645 \\
\hline$R^{a}(I>2 \sigma(I))$ & $\begin{array}{l}R_{1}=0.0731 \\
\mathrm{w} R_{2}=0.1668\end{array}$ & $\begin{array}{l}R_{1}=0.0603 \\
\mathrm{w} R_{2}=0.1840\end{array}$ \\
\hline$R^{a}$ (all data) & $\begin{array}{l}R_{1}=0.0966 \\
\mathrm{w} R_{2}=0.1781\end{array}$ & $\begin{array}{l}R_{1}=0.0654 \\
\mathrm{w} R_{2}=0.1896\end{array}$ \\
\hline \multicolumn{3}{|c|}{$\begin{array}{l}{ }^{a} R 1=\sum\left|F_{\mathrm{o}}\right|-\left|F_{\mathrm{c}}\right| \sum\left|F_{\mathrm{o}}\right| . w R 2=\left[\sum w\left[\left(F_{\mathrm{o}}{ }^{2}-F_{\mathrm{c}}{ }^{2}\right)^{2}\right] / \sum \mid\left[w\left(F_{\mathrm{o}}{ }^{2}\right)^{2}\right]\right]^{1 / 2} \\
w=1 /\left[\sum^{2}\left(F_{\mathrm{o}}{ }^{2}\right)+(0.075 P)^{2}\right], \text { where } P=\left[\max \left(F_{\mathrm{o}}{ }^{2}, 0\right)+2 F_{\mathrm{c}}{ }^{2}\right] / 3\end{array}$} \\
\hline
\end{tabular}

diffractometer using a graphite monochromator with Mo-K $\alpha$ radiation $(\lambda=0.71070 \AA)$. The data was collected at $100 \mathrm{~K}$ using an Oxford Cryostream low temperature device. Data reduction were performed using DENZO-SMN. ${ }^{24}$ The structure was solved by direct methods using SIR $97^{20}$ and refined by semi-empirical from equivalents with anisotropic displacement parameters for the non-H atoms using SHELXL-97. ${ }^{21}$ The hydrogen atoms on carbon were calculated in ideal positions with isotropic displacement parameters set to $1.2 \mathrm{xUeq}$ of the attached atom. Neutral atom scattering factors and values used to calculate the linear absorption coefficient are from the International Tables for X-ray Crystallography. ${ }^{23}$

\section{Calculation of NMR shielding tensors of 1}

The molecular geometry of $\mathbf{1}$ was optimized at the DFT level of theory using the B3LYP hybrid functional ${ }^{25}$ with the Gaussian 03 and GaussView 4.1 programs. ${ }^{26}$ The basis set employed was the SDD basis set utilizing the default parameters included in this program. ${ }^{27}$ The geometric parameters of the optimized geometry determined by this method closely matched those determined by single-crystal X-ray diffraction. The NMR shielding tensors were then calculated in a series of single-point energy calculations using the optimized structure as a starting point and systematically varying the torsion angle between the central pyridine ring and the unbound pyrazole ring leaving all other geometric parameters
Table 3 Selected bond lengths $(\AA)$ and angles $\left({ }^{\circ}\right)$ for $\mathbf{L}$

\begin{tabular}{llll}
\hline S1A-C1A & $1.725(3)$ & C3AC-C4AC & $1.330(1)$ \\
S1A-C4A & $1.702(6)$ & S1AF-C1AF & $1.711(4)$ \\
C1A-C2A & $1.355(7)$ & S1AF-C4AF & $1.726(6)$ \\
C1A-C24 & $1.459(4)$ & C1AF-C2AF & $1.339(8)$ \\
C2A-C3A & $1.450(1)$ & C1AF-C31 & $1.462(5)$ \\
C3A-C4A & $1.340(1)$ & C2AF-C3AF & $1.420(1)$ \\
S1AA-C1AA & $1.718(3)$ & C3AF-C4AF & $1.339(9)$ \\
S1AA-C4AA & $1.763(6)$ & N12-C43 & $1.460(4)$ \\
C1AA-C2AA & $1.318(6)$ & N12-N2 & $1.359(4)$ \\
C1AA-C24A & $1.459(4)$ & N14-C40 & $1.459(4)$ \\
C2AA-C3AA & $1.409(9)$ & N14-N11 & $1.357(3)$ \\
C3AA-C4AA & $1.364(9)$ & C19-C30-C26 & $128.2(2)$ \\
N1-C52 & $1.466(4)$ & C23-C27-C33 & $127.1(2)$ \\
N1-N7 & $1.357(7)$ & N6-C23-C27 & $114.9(2)$ \\
N9-C3 & $1.458(4)$ & N6-C19-C30 & $116.5(2)$ \\
N9-N13 & $1.356(3)$ & N7-N1-C52 & $118.1(2)$ \\
S1AC-C1AC & $1.685(4)$ & N13-N9-C3 & $118.5(2)$ \\
S1AC-C4AC & $1.680(6)$ & S1A-C1A-C24 & $118.1(2)$ \\
C1AC-C2AC & $1.390(1)$ & C2A-C1A-C24 & $131.5(4)$ \\
C1AC-C31C & $1.452(3)$ & S1AA-C1AA-C24A & $123.6(2)$ \\
C2AC-C3AC & $1.460(1)$ & C2AA-C1AA-C24A & $123.7(3)$ \\
\hline
\end{tabular}

Table 4 Selected bond lengths $(\AA)$ and angles $\left({ }^{\circ}\right)$ for 1

\begin{tabular}{llll}
\hline $\operatorname{Re}(1)-\mathrm{C}(23)$ & $1.895(6)$ & $\mathrm{C}(22)-\operatorname{Re}(1)-\mathrm{N}(3)$ & $174.3(2)$ \\
$\operatorname{Re}(1)-\mathrm{C}(22)$ & $1.902(6)$ & $\mathrm{C}(24)-\operatorname{Re}(1)-\mathrm{N}(3)$ & $94.0(2)$ \\
$\operatorname{Re}(1)-\mathrm{C}(24)$ & $1.917(6)$ & $\mathrm{N}(4)-\operatorname{Re}(1)-\mathrm{N}(3)$ & $74.14(18)$ \\
$\operatorname{Re}(1)-\mathrm{N}(4)$ & $2.135(5)$ & $\mathrm{C}(23)-\operatorname{Re}(1)-\mathrm{Br}(1)$ & $90.38(17)$ \\
$\operatorname{Re}(1)-\mathrm{N}(3)$ & $2.259(4)$ & $\mathrm{C}(22)-\operatorname{Re}(1)-\mathrm{Br}(1)$ & $93.20(16)$ \\
$\operatorname{Re}(1)-\mathrm{Br}(1)$ & $2.6222(6)$ & $\mathrm{C}(24)-\operatorname{Re}(1)-\mathrm{Br}(1)$ & $176.81(19)$ \\
$\mathrm{C}(23)-\operatorname{Re}(1)-\mathrm{C}(22)$ & $86.2(2)$ & $\mathrm{N}(4)-\operatorname{Re}(1)-\mathrm{Br}(1)$ & $83.62(13)$ \\
$\mathrm{C}(23)-\operatorname{Re}(1)-\mathrm{C}(24)$ & $90.8(3)$ & $\mathrm{N}(3)-\operatorname{Re}(1)-\mathrm{Br}(1)$ & $82.87(11)$ \\
$\mathrm{C}(22)-\operatorname{Re}(1)-\mathrm{C}(24)$ & $89.8(2)$ & $\mathrm{C}(8)-\mathrm{N}(3)-\operatorname{Re}(1)$ & $127.8(4)$ \\
$\mathrm{C}(23)-\operatorname{Re}(1)-\mathrm{N}(4)$ & $170.6(2)$ & $\mathrm{C}(12)-\mathrm{N}(3)-\operatorname{Re}(1)$ & $113.7(4)$ \\
$\mathrm{C}(22)-\operatorname{Re}(1)-\mathrm{N}(4)$ & $101.3(2)$ & $\mathrm{C}(13)-\mathrm{N}(4)-\mathrm{N}(5)$ & $105.5(5)$ \\
$\mathrm{C}(24)-\operatorname{Re}(1)-\mathrm{N}(4)$ & $94.9(2)$ & $\mathrm{C}(13)-\mathrm{N}(4)-\operatorname{Re}(1)$ & $118.0(4)$ \\
$\mathrm{C}(23)-\operatorname{Re}(1)-\mathrm{N}(3)$ & $98.0(2)$ & $\mathrm{N}(5)-\mathrm{N}(4)-\operatorname{Re}(1)$ & $136.3(4)$ \\
\hline
\end{tabular}

unchanged. The torsion angle was varied between $-180^{\circ}$ and $180^{\circ}$ performing a calculation at $20^{\circ}$ intervals (see $\mathrm{ESI} \dagger$ for full plot). The relative chemical shifts were determined by calibrating the calculated NMR shielding tensors to the value determined for TMS which was calculated using the same computational method. ${ }^{28}$

\section{Conclusions}

In summary, we herein report the synthesis and characterization of a novel bromo tricarbonyl rhenium(I) complex with a thiophenefunctionalized bis(pyrazolyl) pyridine ligand. The trinitrogen donor ligand binds to the $f a c$-rhenium tricarbonyl fragment in a bidentate fashion leaving one pyrazolyl uncoordinated and breaking the symmetry of the ligand. The intense emission profiles in solution and the solid-state are attributed primarily to ${ }^{3} \mathrm{MLCT}$ with some ${ }^{3} \mathrm{LC}\left(\pi \rightarrow \pi^{*}\right)$ character observed. Current efforts are focused on electropolymerizion of $\mathbf{1}$ and derivatives thereof for application in polymer light-emitting diodes (PLEDs).

\section{Acknowledgements}

We gratefully acknowledge the Robert A. Welch Foundation (F-1631), the Petroleum Research Fund administered by the 
American Chemical Society (47022-G3), the National Science Foundation (CHE-0639239, CHE-0741973 and CHE-0847763), the American Heart Association (0765078Y), the UT-CNM and UT-Austin for financial support of this research.

\section{Notes and references}

1 (a) M. S. Wrighton and D. L. Morse, J. Am. Chem. Soc., 1974, 96, 998; (b) M. P. Coogan, V. Fernández-Moreira, J. B. Hess, S. J. A. Pope and C. Williams, New J. Chem., 2009, 33, 1094; (c) D. J. Stufkens and A. Vlček, Coord. Chem. Rev., 1998, 177, 127; (d) A. J. Lees, Coord. Chem. Rev., 1998, 177, 3; (e) T. J. Henly, Coord. Chem. Rev., 1989, 93, 269; (f) G. L. Geoffroy and M. S. Wrighton, Organometallic Photochemistry, Academic Press, New York, 1979; $(\mathrm{g}) \mathrm{K}$. Kalyanasundaram, Photochemistry of Polypyridine and Porphyrin Complexes, Academic Press, London, 1992; (h) B. P. Sullivan, J. Phys. Chem., 1989, 93, 24; (i) L. Wallace, C. Woods and D. P. Rillema, Inorg. Chem., 1995, 34, 2875; (j) P. J. Giordano and M. S. Wrighton, J. Am. Chem. Soc., 1979, 101, 2888; $(k)$ L. A. Worl, R. Duesing, P. Chen, L. Della Ciana and T. J. Meyer, J. Chem. Soc., Dalton Trans., 1991, 849; (l) D. R. Striplin and G. A. Crosby, Chem. Phys. Lett., 1994, 221, 426.

2 (a) S. Ranjan, S.-Y. Lin, K.-C. Hwang, Y. Chi, W.-L. Ching and C.-S. Liu, Inorg. Chem., 2003, 42, 1248; (b) J. C. Luong, L. Nadjo and M. S. Wrighton, J. Am. Chem. Soc., 1978, 100, 5790; (c) P. G. Giordano, S. M. Fredericks, M. S. Wrighton and D. L. Morse, J. Am. Chem. Soc., 1978, 100, 2257; (d) A. J. Lees, Chem. Rev., 1987, 87, 711; (e) A. P. Zipp, L. Sacksteder, J. Streich, A. Cook, J. N. Demas and B. A. Degraff, Inorg. Chem., 1993, 32, 5629.

3 (a) M. Zhang, P. Lu, X. Wang, L. He, H. Xia, W. Zhang, B. Yang, L. Liu, L. Yang, M. Yang, Y. Ma, J. Feng, D. Wang and N. Tamai, J. Phys. Chem. B, 2004, 108, 13185; (b) J. Guerrero, O. E. Piro, E. Wolcan, M. R. Feliz, G. Ferraudi and S. A. Moya, Organometallics, 2001, 20, 2842; (c) L. A. Lucia, K. Abboud and K. S. Schanze, Inorg. Chem., 1997, 36, 6224; (d) D. M. Roundhill, Photochemistry and Photophysics of Metal Complexes, Plenum, New York, 1994.

4 (a) M. A. Baldo, D. F. O'Brian, Y. You, A. Shoustikov, S. Sibley, M. E. Thompson and S. R. Forrest, Nature, 1998, 395, 151; (b) M. A. Baldo, S. Lamansky, P. E. Burrows, M. E. Thompson and S. R. Forrest, Appl. Phys. Lett., 1999, 75, 4; (c) C. Adachi, M. A. Baldo, S. R. Forrest and M. E. Thompson, Appl. Phys. Lett., 2000, 77, 904; (d) J. C. Ostrowski, M. R. Robinson, A. J. Heeger and G. C. Bazan, Chem. Commun., 2002, 784; (e) Y. Ma, H. Zhang, J. Shen and C.-M. Che, Synth. Met., 1998, 94, 245; $(f)$ S. Bernhard, X. Gao, G. G. Malliaras and H. D. Abruna, Adv. Mater., 2002, 14, 433; $(g)$ X. Jiang, A. K.-Y. Jen, B. Carlson and L. R. Dalton, Appl. Phys. Lett., 2002, 80, 713; (h) R. C. Kwong, S. Sibley, T. Dubovoy, M. Baldo, S. R. Forrest and M. E. Thompson, Chem. Mater., 1999, 11, 3709; (i) S. C. Chan, M. C. W. Chan, Y. Wang, C.-M. Che, K. K. Cheung and N. Zhu, Chem.-Eur. J., 2001, 7, 4180; (j) W. Lu, B.-X. Mi, C. W. Chan, Z. Hui, N. Zhu, S.-T. Lee and C.-M. Che, Chem. Commun., 2002, 206.

5 (a) A. J. Amoroso, M. P. Coogan, J. E. Dunne, V. Fernández-Moreira, J. B. Hess, A. J. Hayes, D. Lloyd, C. Millet, S. J. A. Pope and C. Williams, Chem. Commun., 2007, 3066; (b) N. B. Thornton and K. S. Schanze, Inorg. Chem., 1993, 32, 4994; (c) A. J. Amoroso, R. J. Arthur, M. P. Coogan, J. B. Court, V. Fernández-Moreira, A. J. Hayes, D. Lloyd, C. Millet and S. J. A. Pope, New J. Chem., 2008, 32, 1097; (d) K. K. Lo, T. K.-M. Lee, J. S.-Y. Lo, W.-L. Poon and S.-H. Cheng, Inorg. Chem., 2008, 47, 200; (e) X. Q. Guo, F. N. Castellano, L. Li, H. Szymacinski, J. R. Lakowicz and J. Sipior, Anal. Biochem., 1997, 254, 179; $(f)$ K. K.-W. Lo, K. H.-K. Tsang, K.-S. Sze, C.-K. Chung, T. K.-M. Lee, K. Y. Zhang, W.-K. Hui, C.-K. Li, J. S.-Y. Lau, D. C.-M. Ng and N. Zhu, Coord. Chem. Rev., 2007, 251, 2292; (g) K. K.-W. Lo, K. H.-K. Tsang and N. Zhu, Organometallics, 2006, 25, 3220; (h) J. S.-Y. Lau, P.-K. Lee, K. H.-K. Tsang, C. H.-C. Ng, Y.-W. Lam, S.-H. Cheng and K. K.-W. Lo, Inorg. Chem., 2009, 48, 708.

6 (a) J Hawecker, J. M. Lehn and R. J. Ziessel, J. Chem. Soc., Chem. Commun., 1983, 536; (b) J. Hawecker, J. M. Lehn and R. J. Ziessel, J. Chem. Soc., Chem. Commun., 1984, 328; (c) C. Kutal, M. A. Weber, G. Ferraudi and D. Geiger, Organometallics, 1985, 4, 2161; (d) C. Kutal, A. J. Corbin and G. Ferraudi, Organometallics, 1987, 6, 553; (e) S.-S. Sun and A. J. Lees, J. Am. Chem. Soc., 2000, 122, 8956; (f) A. Juris, S. Campagna, I. Bidd, J.-M. Lehn and R. Ziessel, Inorg. Chem., 1988,
27, 4007; $(g)$ T. R. O’Toole, L. D. Margerum, T. D. Westmoreland, W. J. Vining, R. W. Murray and T. J. Meyer, J. Chem. Soc., Chem. Commun., 1985, 1416; (h) V. W.-W. Yam, V. C.-Y. Lau and K.-K. Cheung, Organometallics, 1995, 14, 2749.

7 S. Viswanathan and A. de Bettencourt-Dias, Inorg. Chem., 2006, 45, 10138.

8 D. E. Fenton, J. R. Tate, U. Casellato, S. Tamburini, P. A. Vigato and M. Vidali,, Inorg. Chim. Acta, 1984, 83, 23.

9 (a) Y. Zhou, W. Chen and D. Wang, Dalton Trans., 2008, 1444; (b) J.-Y. Dong and T.-P. You, Acta Crystallogr., Sect. E: Struct. Rep. Online, 2008, 64, o820; (c) D. Zabel, A. Schubert, G. Wolmershäuser, R. L. Jones and W. R. Thiel, Eur. J. Inorg. Chem., 2008, 3648.

10 F. A. Cotton, Chemical Applications of Group Theory, Third Edition, Wiley, New York, 1990

11 (a) P. J. Heard, P. M. King, A. D. Bain, P. Hazendonk and D. A. Tocher, J. Chem. Soc., Dalton Trans., 1999, 4495; (b) A. Gelling, K. G. Orrell, A. G. Osborne and V. Šik, J. Chem. Soc., Dalton Trans., 1998, 937; (c) P. J. Heard and C. Jones, J. Chem. Soc., Dalton Trans., 1997, 1083; (d) E. W. Abel, K. A. Hylands, M. D. Olsen, K. G. Orrell, A. G. Osborne, V. Šik and G. N. Ward, J. Chem. Soc., Dalton Trans., 1994, 1079.

12 (a) B. Machura, R. Penczek and R. Kruszynski, Polyhedron, 2007, 26, 2470; (b) Q. Ge, T. C. Corkery, M. G. Humphrey, M. Samoc and T. S. A. Hor, Dalton Trans., 2009, 6192.

13 (a) S.-T. Lam, N. Zhu and V. W.-W. Yam, Inorg. Chem., 2009, 48, 9664; (b) M.-W. Louie, H.-W. Liu, M. H.-C. Lam, T.-C. Lau and K. K.-W. Lo, Organometallics, 2009, 28, 4297; (c) D. V. Partyka, N. Deligonul, M. P. Washington and T. G. Gray, Organometallics, 2009, 28, 5837; (d) L. Sacksteder, A. P. Zipp, E. A. Brown, J. Streich, J. N. Demas and B. A. Degraff, Inorg. Chem., 1990, 29, 4335; (e) M. R. Waterland, T. J. Simpson, K. C. Gordon and A. K. Burrell, J. Chem. Soc., Dalton Trans., 1998, 185.

14 (a) R. A. Kirgan, B. P. Sullivan and D. P. Rillema, Top. Curr. Chem., 2007, 281, 45; (b) V. W.-W. Yam, V. C.-Y. Lau and L.-X. Wu, J. Chem. Soc., Dalton Trans., 1998, 1461; (c) M. K. Itokazu, A. S. Polo, D. L. A. de Faria, C. A. Bignozzi and N. Y. M. Iha, Inorg. Chim. Acta, 2001, 313, 149; (d) E. Wolkan, G. Torchia, J. Tocho, O. E. Piro, P. Juliarena, G. Ruiz and M. R. Feliz, J. Chem. Soc., Dalton Trans., 2002, 2194; (e) J. V. Casper and T. J. Meyer, J. Phys. Chem., 1983, 87, 952; (f) Y. Wang, B. T. Hauser, M. M. Rooney, R. D. Burton and K. S. Schanze, J. Am. Chem. Soc., 1993, 115, 5675; $(g)$ K. K.-W. Lo, W.-K. Hui, D. C.-M. Ng and K.-K. Cheung, Inorg. Chem., 2002, 41, 40.

15 The heavily mixed excited state of $\mathbf{1}$ is also supported by variable wavelength excitation experiments to rule out non-selective excitation. Utilizing a $\lambda_{\text {ex }}$ of up to $390 \mathrm{~nm}$, which is the experimental limit to allow the observation of the high energy emission peak, consistently displays both ${ }^{3} \mathrm{LC}$ and ${ }^{3} \mathrm{MLCT}$ emission peaks.

16 H. D. Stoeffler, N. B. Thornton, S. L Temkin and K. S. Schanze, J. Am. Chem. Soc., 1995, 117, 7119 .

17 R. Alberto, A. Egli, U. Abram, K. Hegetschweiler, V. Gramlich and P. A. Schubiger, J. Chem. Soc., Dalton Trans., 1994, 2815.

18 A. Aebischer, F. Gumy and J.-C. G. Bunzli, Phys. Chem. Chem. Phys., 2009, 11, 1346.

19 CrystalClear 1.40 (2008). Rigaku Americas Corporation, The Woodlands, TX.

20 A. Altomare, M. C. Burla, M. Camalli, G. L. Cascarano, C. Giacovazzo, A. Guagliardi, A. G. G. Moliterni, G. Polidori and R. Spagna, J. Appl. Crystallogr., 1999, 32, 115.

21 G. M. Sheldrick, SHELXL97, Program for the Refinement of Crystal Structures, University of Göttingen, Göttingen, Germany, 1994.

$22 R_{\mathrm{w}}\left(F^{2}\right)=\left\{\sum w\left(\left|F_{\mathrm{o}}\right|^{2}-\left|F_{\mathrm{c}}\right|^{2}\right)^{2} / \sum w\left(\left|F_{\mathrm{o}}\right|\right)^{4}\right\}^{1 / 2}$ where $\mathrm{w}$ is the weight given each reflection. $\left.R(F)=\sum\left(\left|F_{\mathrm{o}}\right|-\left|F_{\mathrm{c}}\right|\right) / \sum\left|F_{\mathrm{o}}\right|\right\}$ for reflections with $F_{\mathrm{o}}>4\left(\sigma\left(F_{\mathrm{o}}\right)\right) . S=\left[\sum w\left(\left|F_{\mathrm{o}}\right|^{2}-\left|F_{\mathrm{c}}\right|^{2}\right)^{2} /(n-p)\right]^{1 / 2}$, where $n$ is the number of reflections and $\mathrm{p}$ is the number of refined parameters.

23 A. J. C. Wilson, International Tables for X-ray Crystallography, Kluwer Academic Press, Boston, vol. C, 1992, Tables 4.2.6.8 and 6.1.1.4.

24 Z. Otwinowski, W. Minor, Macromolecular Crystallography, part A, C. W. Carter Jr., R. W. Sweets, Academic Press, vol. 276, 1997, 307.

25 A. D. Becke, J. Chem. Phys., 1993, 98, 5648.

26 M. J. Frisch, G. W. Trucks, H. B. Schlegel, G. E. Scuseria, M. A. Robb, J. R. Cheeseman, J. A. Montgomery, Jr., T. Vreven, K. N. Kudin, J. C. Burant, J. M. Millam, S. S. Iyengar, J. Tomasi, V. Barone, B. Mennucci, M. Cossi, G. Scalmani, N. Rega, G. A. Petersson, H. Nakatsuji, M. Hada, M. Ehara, K. Toyota, R. Fukuda, J. Hasegawa, M. Ishida, T. Nakajima, Y. Honda, O. Kitao, H. Nakai, M. Klene, X. 
Li, J. E. Knox, H. P. Hratchian, J. B. Cross, V. Bakken, C. Adamo, J. Jaramillo, R. Gomperts, R. E. Stratmann, O. Yazyev, A. J. Austin, R. Cammi, C. Pomelli, J. Ochterski, P. Y. Ayala, K. Morokuma, G. A. Voth, P. Salvador, J. J. Dannenberg, V. G. Zakrzewski, S. Dapprich, A. D. Daniels, M. C. Strain, O. Farkas, D. K. Malick, A. D. Rabuck, K. Raghavachari, J. B. Foresman, J. V. Ortiz, Q. Cui, A. G. Baboul, S. Clifford, J. Cioslowski, B. B. Stefanov, G. Liu, A. Liashenko, P. Piskorz, I. Komaromi, R. L. Martin, D. J. Fox, T. Keith, M. A.
Al-Laham, C. Y. Peng, A. Nanayakkara, M. Challacombe, P. M. W. Gill, B. G. Johnson, W. Chen, M. W. Wong, C. Gonzalez and J. A. Pople, GAUSSIAN 03 (Revision D.01), Gaussian, Inc., Wallingford, CT, 2004.

27 P. Fuentealba, H. Preuss, H. Stoll and L. v. Szentpaly, Chem. Phys. Lett., 1982, 89, 418.

28 J. B. Foresman and A. Frisch, Exploring Chemistry with Electronic Structure Methods, 2nd Ed., 1996. 